\title{
EXPLICIT COMMUNICATION: AN INTEREST AND BELIEF-BASED MODEL
}

\author{
MARCO CRUCIANI \\ marco.cruciani@unitn.it \\ Department of Engineering and Computer Science, \\ University of Trento
}

\begin{abstract}
The paper presents an inferential model of explicit communication based on the speaker's interests and the addressee's beliefs. After the introduction, the paper sets out some notions concerning explicit communication within the frameworks of truth-conditional pragmatics and relevance theory. The third section describes the phenomenon of semantic underdeterminacy, and the fourth section introduces non-demonstrative inferences in communication. The fifth section presents the model. The main notions involved are the speaker's intended meaning and the addressee's intended meaning. The former notion is centered on the speaker's interest in situation: a speaker intends the meaning of an utterance on the basis of a partial order of preference with respect to a set of contextually plausible meanings. The latter notion is centered on the addressee's communicative inference, which is based on the addressee's belief about the speaker's interest. The paper takes the notion of interest from cognitive social theory, the notion of meaning from semantics, and the notion of explicit meaning from pragmatics; and it uses the notion of communicative inference for explicit meaning in partial accordance with relevance theory. In the sixth section, the paper argues in favor of the inferential approach compared with the associative approach in determination of "what is said." The paper's method is conceptual analysis of declarative utterances used in communicative situations. The main finding of the paper has been to show that, in contextual underdeterminacy cases, speaker's interest is a determining factor in communicative processes.
\end{abstract}

Keywords: states of affairs; truth-conditions; semantic underdeterminacy; contextual underdeterminacy; speaker's interest; goal-conditions; speaker's intended meaning; addressee's belief; communicative inference; addressee's intended meaning; shared intended meaning; explicit communication.

How to cite: Cruciani, Marco (2018). "Explicit Communication: An Interest and Belief-based Model," Linguistic and Philosophical Investigations 17: 50-70.

Received 17 February 2017 • Received in revised form 19 May 2017

Accepted 20 May 2017 • Available online 15 June 2017 


\section{Introduction ${ }^{1}$}

Communication is a phenomenon which pervades all human activity. It is studied by various disciplines from different theoretical perspectives. Whatever the perspective taken, however, studying communication involves investigation of a complex phenomenon which by its nature requires dialogue among disciplines. Some important theories in philosophy, linguistics and cognitive science share the idea that full understanding of verbal communication requires understanding the role of the nonlinguistic knowledge tied to the situation in which a linguistic expression is uttered (Travis, 1975; Searle, 1980; Grice, 1989; Levinson, 2000; Carston, 2002; Recanati, 2010; Bach, 2010; Wilson and Sperber, 2012).

Although in recent years these approaches to the study of language have gained increasing consensus, still firmly established in the philosophy of language is the "code model" (e.g. literalism). In other words, it is still widely believed that syntactic and semantic rules suffice to decode the meaning of a natural language expression (see the indexicalism of Stanley, 2000, and the minimalism of Cappelen and Lepore, 2005).

In the literalist framework, the explicit level of communication, "what is said," is strictly related to the conventional meaning of the expressions appearing in a sentence. It differs in only two respects: if there are indexical and demonstrative expressions, they must be saturated; if there are structural ambiguities and homonymous expressions, it is necessary to establish what meaning or syntactic structure is relevant in the context of utterance. Once the explicit level has been identified, it is possible to determine a possible implicit level at which the speaker's communicative intentions have a role. On this view, the sentences of a language have fixed truth conditions entirely determined by the syntax and semantics. Only the decodification process makes it possible to assign the semantic content (truth conditions), and it does so in a manner completely independent of the speaker's intentions. Literalism thus draws a distinction between, on the one hand, the obligatory or semantic processes (saturation) which allow determination of the level of the proposition literally expressed by an utterance, and on the other, the optional or pragmatic processes (enrichment, transfer and implicatures) which make it possible to determine an additional and implicit level of sense.

This paper contends that the speaker's intentions and contextual assumptions also contribute to determination of "what is said": that is, it argues in favor of the contribution of the speaker's intentions and the pragmatic context to the truthconditional content of the utterance (a contribution made before the semantic composition). In particular, the paper argues for the context-dependence of meaning, and it proposes a model of explicit communication in which the process of determining "what is said" is guided by the addressee's recognition of the speaker's nonlinguistic goals, which trigger information relative to the speaker's non-linguistic interests.

In summary, this research is relevant because it shows that in the explicit (and not only implicit) communication processes the determination of the intended 
meaning of an expression does not depend exclusively on the decoding of linguistic items, that is, syntax and semantics, but also on non-linguistic items related to the context of utterance (semantic underdeterminacy). Moreover, it is more relevant to the paper's goals that, in some cases, it is not possible to determine the intended meaning even on the basis of non-linguistic information about the context of utterance (contextual underdeterminacy). In the latter cases, we need to recourse to specific information about the speaker, that is, his/her interest in situation. Another relevant question faced by the paper is that, in cases of contextual underdeterminacy, the associative approach seems to be less effective compared with the inferential approach.

The scope of the model presented here relates to communicative situations in which contextual underdetermination is present and the addressee has specific information about the speaker's interests, from which he/she obtains an order of preference between contextually plausible meanings.

\section{What Is Said}

In recent years, studies by pragmatists and semanticists have given rise to diverse standpoints about different aspects related to the context-dependence of meaning (e.g. indexicality, reference assignment, literal meaning, semantic underdeterminacy, context-sensitivity, pragmatic intrusion, unarticulated constituents, semantics/ pragmatics distinction, "what is said"/"what is implicated" distinction, etc.) (Perry, 2000; Stanley, 2000; Recanati, 2002a, 2004a, 2010; Bianchi, 2004; Bach, 2004, 2012; Szabó, 2005; Cappelen and Lepore, 2005; Cappelen, 2007; Carston, 2008; Gaucker, 2012; Borg, 2012; Corazza and Dokic, 2012; Stojnic and Lepore, 2013; Belleri, 2014; Stalnaker, 2014). There is also lively debate within pragmatics which treats and extends the previous issues: for instance, "what is said" vs. explicature, associative vs. inferential method, primary and secondary pragmatic processes, topdown vs. bottom-up processes, explicature vs. impliciture, ad hoc concepts construction, mutual adjustment, backward/forward inference, meta-representations in communication, radical vs. moderate contextualism, etc. (Sperber and Wilson, 1986, 2002; Levinson, 2000; Bezuidenhout, 2002; Recanati, 2007, 2010, 2012; Carston, 2002, 2007, 2009; Wilson and Carston, 2007; Bach, 2010; Mazzone, 2011; Mazzarella 2011; Wilson and Sperber, 2012; Carston and Hall, 2012; Belleri, 2013; Hall, 2014).

This article will pay especial attention to the truth-conditional pragmatics of Recanati (2010) and the inferential approach to communication of Sperber and Wilson's (2012) relevance theory. These two solid approaches are based on similar frameworks but propose explanatory models which differ in various respects. There follows a brief description of some of the concepts used by the two approaches of relevance to the paper and some of their main differences.

In particular, of relevance to the purpose of the paper is the debate concerning the nature of the "primary" pragmatic processes, i.e. the processes that contribute to 
determination of the explicit meaning of an utterance ("what is said" in Recanati's terms and "explicature" in Sperber and Wilson's $\left.{ }^{2}\right)$. Relevance theory has developed a unified inferential account of primary (i.e. explicatures) and secondary (i.e. implicatures) pragmatic processes. Instead, Recanati conceives two different processing systems: for primary processes, there is an associative system, which guides the determination of "what is said;" and for secondary processes, there is an inferential system, which recovers "what is implicated."

According to truth-conditional pragmatics, primary pragmatic processes are ruled by accessibility and constrained by semantic associations and world knowledge structures (i.e. schemata). On Recanati's view, "what is said" is a proposition determined by decoding and semantic associations, and it is used as a premise for inferring "what is implicated" (Recanati, 2010). ${ }^{3}$ Of great importance in Recanati's framework is the notion of accessibility. When an utterance is interpreted, the possible candidates for the meaning of a word are activated in parallel, and they compete with each other. The winner is the one most accessible to the addressee. A meaning can be more accessible and immediate to the addressee because, for example, it relates to his/her activities and knowledge, and is therefore activated more than the other competing meanings. However, during the interpretation process it may happen that the meaning most accessible to the addressee is not consistent with the communicative situation. At this point, an accessibility shift is triggered on the basis of the conceptual coherence of another of the candidate meanings with the schemata activated by the elements of the communication situation (e.g. words, contextual factors). The interpretative process is thus realigned with the communication (content sharing). In Recanati's view, the composition of the utterance's meaning may occur after the lexical modulation (e.g., free enrichment). In this case, the modulation has an effect on the truth-conditional content of the sentence uttered. When the pragmatic processes of lexical modulation intervene before the semantic composition, we have a pragmatic intrusion which delivers intuitive truthconditions (put otherwise, we have a form of contextualism). Finally, the process of determining "what is said" is characterized as sub-personal: only the output from the process (i.e., "what is said") is available to the participants in the communicative exchange (see Recanati, 2004b).

According to relevance theory, an utterance (like every ostensive-inferential communicative act) communicates the presumption of its own optimal relevance (communicative principle of relevance), which guides the derivation of explicatures, contextual assumptions and implicatures. On Wilson and Sperber's view, an explicature is a proposition determined by decoding and inference, and it is connected to implicature by a process of mutual parallel adjustment (Wilson and Sperber, 2012). ${ }^{4}$ In relevance theory's framework, the inputs to the interpretative process are identified and processed by the addressee according to their cognitive relevance. An input is relevant to an addressee when its processing in a context yields a positive cognitive effect: that is, a worthwhile difference to the addressee's representation of the world. An input is optimally relevant if and only if it justifies the processing 
effort of the addressee, and it is the one most compatible with the capacities and preferences of the speaker. When the level of relevance is optimal, the comprehension procedure is triggered. The comprehension procedure is based on a path of least effort in testing possible interpretations (e.g., ambiguity resolution, reference assignment) in order of accessibility, and it stops when the addressee's expectations of relevance are satisfied (Wilson and Sperber, 2012; Wilson, 2014). The comprehension procedure is a heuristic and automatic procedure for achieving an interpretation of an utterance that confirms the presumption of optimal relevance, and it is conceived as a specialized comprehension module which is part of a broader mind-reading module dedicated to attributing mental states in order to explain and predict behavior (see Wilson 2014; Wilson and Sperber, 2012).

In pragmatics, the most typical and pervasive primary process affecting the truthconditions of an utterance is free enrichment: that is, a kind of lexical modulation that affects "what is said" (Recanati, 2010). It gives an interpretation more specific than the literal one; that is, the process of free enrichment outputs a denotation of an expression that is a subset of the initial denotation (Carston, 1997). In relevance theory, this kind of lexical modulation is called "narrowing," and it contributes to explicatures. ${ }^{5}$ It is driven by the search for relevance, as are all pragmatic tasks and processes (e.g., ambiguity resolution, implicatures). On Recanati's view, free enrichment is a top-down process; that is, a contextually-driven and optional one. In contrast, a bottom-up process is a signal-driven process which is mandatory to obtain a truth-evaluable utterance. Typically, a bottom-up process consists in the saturation of indexical expressions, where the information used is triggered by variables in the form of a sentence (e.g., "I", "here"). ${ }^{6}$ Instead, the process of free enrichment is not triggered by variables in the form of sentence; rather, it is triggered for purely pragmatic reasons, that is, in order to understand what the speaker is saying.

In short, the current debate is animated by numerous questions. For example: What is the contribution of context to the determination of propositional content? How is the relevant non-linguistic information triggered? And how is it used? Is it the premise of a non-demonstrative inference, or does it activate a frame that associates concepts? Etc.

The following sections briefly present the phenomenon of semantic underdeterminacy; the communicative inferences for explicit meaning; the interest and belief-based model of explicit communication, and explanation of how it works. The final section argues in favor of the role of the speaker's interest and the addressee's beliefs in explicit communication. 


\section{Semantic Underdeterminacy, Non-linguistic Information and Contextual Underdeterminacy}

This section briefly illustrates the phenomenon of semantic underdeterminacy, and outlines some differences between semantic perspective and pragmatic perspectives concerning the role of non-linguistic information in meaning determination.

Semantic underdeterminacy occurs when the conventional meaning of a sentence uttered by a speaker underdetermines the proposition explicitly expressed by the utterance (Travis, 1975; Searle, 1980). The question is whether conventional meaning, obtained by semantic conventions and linguistic rules, is sufficient to provide truth-conditions or whether other items are required as well. In other words, is it sufficient to know semantic conventions and linguistic rules or is it necessary to know elements of the specific situation of utterance?

On a semantic view, conventional meaning and a small number of contextual variables are sufficient to determine the truth-conditions of a sentence (see Stanley, 2000; Cappelen and Lepore, 2005). In this view, few types of expressions are considered context-dependent: for example, indexical expressions (e.g. "I", "she", "here", "today"), demonstrative pronouns (e.g. "this", "that", "there"), pronouns used anaphorically, verb tenses, etc. In these cases, information about the objective context of the utterance ${ }^{7}$ is triggered solely by variables positioned in the logical and linguistic form of the sentence. In fact, the context-dependence of meaning is addressed by semantics without contributions from pragmatics: more precisely, without recourse to communicative intentions and the contribution of the context (in the broad sense). From this perspective, the primary pragmatic processes (i.e., lexical modulation) are not necessary for the assignment of reference; they do not intervene before the semantic composition, and hence have no impact on the truthconditions of the sentence.

On a pragmatic view, conventional meaning is not sufficient to determine a unique set of truth-conditions (Recanati, 2010; Sperber and Wilson, 2012). In this view, semantic underdeterminacy is considered pervasive of almost all natural language sentences; or, to put it differently, most natural language sentences are context-sensitive. Hence, we need information about the context of use to complete the conventional meaning and to determine the truth-conditions. More precisely, the current debate in pragmatics centers on the contextual dependence of the meanings of individual words, and how the contextual factors intervening in the assignment of reference contribute to the truth-conditions of the sentence uttered. In short, according to this account, the primary pragmatic processes intervene before the semantic composition, thus contributing to determination of the utterance's (intuitive) truth-conditions.

By "context" - in communication - I mean the information mentally represented (cf. Wilson, 2014) in order to understand linguistic expressions. This information concerns various aspects of the situation in which communication takes place. Some types of contextual information are the following: linguistic information (e.g. the sentence in which a word appears, the text/discourse in which a sentence 
appears); "local" information concerning specific events and the individuals involved in the interaction (e.g., the town's best-known bookshop is holding a sale; "yesterday it rained all along the River Adige;" "the speaker is an angler;" "it is the speaker's birthday"); "general" (encyclopaedic) information relative to shared practices and facts about the world (e.g. "writing books is difficult," "it is usually very damp on the banks of rivers;" "the capital of Italy is Rome"); information gathered directly from the surrounding environment (e.g. "it's raining;" "the speaker is holding a fishing rod;" "there's a large book in the bag").

Specifically, this paper deals with the problem of explicit meaning when a number of interpretations are all plausible in the same combination of contexts, and not with the problem of whether there is a need for non-linguistic information to fix a unique set of truth-conditions. We might call this kind of phenomenon "contextual underdeterminacy."

An example can clarify this point. The issue is as follows: the conventional meaning of a sentence, even without indexical expressions and structural and lexical ambiguity, actually underdetermines the proposition expressed by the sentence. And even with the additional pragmatic contribution of relevant nonlinguistic information, it is not always possible to fix a unique proposition. Consider the following sentence:

(1) "There is water on Mars."

I do not know whether there is water on Mars, but I understand the sentence because I am able to imagine the ways in which there might be water on Mars: for example, in the form of ice on the planet's surface or in the form of gas in its atmosphere. Consequently, sentence (1) can have at least two interpretations (two different sets of truth-conditions); that is, it can be true both if there is water in the form of ice on the surface and if there is water in the form of gas in the atmosphere. ${ }^{8}$ The two sets of truth-conditions correspond to different states of affairs:

a. "There is ice on the surface of Mars."

b. "There is water vapour in the atmosphere of Mars."

Hence, (1) can refer to both states of affairs. This is the case if we consider semantic conventions, but also if we consider the text of the sentence in which the word "water" appears and we use encyclopaedic knowledge (e.g. physical states of water).

In these cases of contextual underdeterminacy, how is it possible to establish which of the two enrichments is the most appropriate in the specific situation? Put otherwise: in communication processes what is it that drives enrichment in the interpretative process in one direction rather than another? This paper argues that if non-linguistic information is not sufficient to determine a unique set of truthconditions (proposition), then, in order to determine the explicit content of com- 
munication, we can take into account the speaker's preferences for the states of affairs which make a sentence true.

Before discussion begins on how preferences for states of affairs contribute to retrieval of the non-linguistic information necessary to determine the explicit meaning, we shall briefly consider the kinds of inferences considered in the model.

\section{Inference of Explicit Meaning}

This section presents communication inferences for explicit communication, i.e., non-demonstrative inferences. Communicative inferences are non-demonstrative because they have a logical structure that does not guarantee the truth of the conclusions, in contrast to deduction. Deduction is a type of inference whereby what is inferred is necessarily true if the premises are true; that is, the truth of the premises logically guarantees the truth of the conclusions. Even if new premises are added, the conclusions remain valid.

The communicative inferences considered here have the structure of abduction. An abduction is an inference where the truth of the premises does not logically guarantee the truth of the conclusion, but guarantees it with respect to the current information and until proof to the contrary is forthcoming. It is possible that new information added to the premises modifies the conclusions. In these terms, abduction violates the property of monotonicity, and the conclusion is defeasible. It is a type of reasoning aimed at obtaining the best explanation given the information available.

In particular, in explicit communication/language understanding, the concern is to infer the meaning that best fits with the contextual assumptions; that is, the best explanation of why the speaker says "what s/he says" in the situation in which the sentence is uttered.

The type of communicative inferences considered here are the following:

$\mathrm{P}_{1}$ : Form and semantic conventions.

$\mathrm{P}_{2}$ : Contextual information.

C: Explicit meaning.

Consider the following sentence:

(2) "The bank is wet."

In (2) the meaning of the word "bank" is not determined, and it can mean a financial institute or land alongside a river. In cases of this kind, the context may provide information with which to select a plausible interpretation. For example, on the one hand, if (2) is uttered by a speaker close to an angler who is about to fish, then "bank" plausibly refers to the land alongside a river and (2) plausibly means that alongside the river there is high humidity; on the other hand, if the speaker 
is near to the doors of a financial institute, then the word "bank" plausibly refers to the institute and (2) plausibly means that the floor of the financial institute has just been washed. In both cases the non-linguistic information is directly perceived from physical surroundings (i.e., the angler and the financial institute). Hence, the meaning of (2) is obtained through an inference composed of two premises: sentence (2) (semantic conventions applied to the linguistic form) and information about the context in which (2) is uttered; the conclusion consists of a unique proposition. The two possible inferences are as follows:

$\mathrm{P}_{1}$ : "The bank is wet."

$\mathrm{P}_{2}$ : Direct perception of the financial institute.

C: "The floor of the financial institute has just been washed".

$\mathrm{P}_{1}$ : "The bank is wet."

$\mathrm{P}_{2}$ : Direct perception of the angler.

C: "There is high humidity alongside the river."

Consider (2) uttered by a speaker close to an angler about to fish: the word "wet" can refer to both high humidity and water on grass, rocks, etc. Here the form or the way in which water is on the bank is not determined. We need further information: for instance, yesterday it rained alongside the river (local knowledge); or generally there is high humidity alongside rivers (encyclopaedic knowledge), to determine the ways in which there is water on the bank. The two possible inferences are the following:

$\mathrm{P}_{1}$ : "The bank is wet."

$\mathrm{P}_{2}$ : Yesterday it rained alongside the river.

C: "There is water on grass, etc. alongside the river."

$\mathrm{P}_{1}$ : "The bank is wet."

$\mathrm{P}_{2}$ : Generally there is high humidity alongside rivers.

C: "There is high humidity alongside the river."

The inferential processes involved in determination of the meaning of (2) are those of resolution of ambiguity and enrichment of truth-conditions. We can infer an interpretation of the word "bank" on the basis of contextual information directly perceived from the physical surroundings, and consequently we can infer an interpretation of the word "wet" on the basis of local or encyclopaedic knowledge.

Note that, in this study, the resolution of ambiguity is treated in inferential terms like any pragmatic task (see Wilson and Carston, 2007), regardless of the type of contextual dependence that it exhibits and the status assigned to it in semantics. ${ }^{9}$ 
Finally, I would stress that it is not necessary for communication that the nonlinguistic information used in the second premise be made available by, or constrained to, the linguistic form of the sentence. It is triggered for pragmatic reasons - that is, to understand what the speaker is saying - and contributes to the utterance's truth-conditions.

\section{The Model}

This section presents a model of explicit communication where the notion of shared intended meaning is based on the speaker's preference for a state of affairs to which a sentence refers, and on the addressee's communicative inference, which involves the addressee's belief about the interest of the speaker in the specific communicative situation.

The two basic theses are the following: 1) given a set of contextually plausible interpretations of an utterance, the speaker's intended meaning is determined by the speaker's situational interests; and 2) the addressee's intended meaning ${ }^{10}$ is inferred by the addressee on the basis of his/her belief about the speaker's interest. Communication is successful when the intended speaker's meaning and the addressee's speaker meaning are shared: that is, when the addressee's inference is based on a true belief about the speaker's interest in situation.

The model takes the notion of interest from cognitive social theory. It thus views an interest as a state of affairs preferred by a speaker because it implies the conditions of possibility of his/her goal (goal-conditions) - this is a modified notion originally proposed by Conte and Castelfranchi (1995). The model also takes the notion of meaning from semantics: that is, a sentence's meaning identifies with the truth-conditions of that sentence; and the meaning of an expression identifies with its contribution to the truth-conditions of the sentence in which it appears.

Speaker's intended meaning. ${ }^{11}$ The notion of speaker's intended meaning of declarative sentences is founded on the relation between the states of affairs in which a sentence is true and the speaker's preferences ordering in regard to the states of affairs in which the sentence is true. A sentence can be true with respect to different sets of truth-conditions, which correspond to different states of affairs. The state of affairs preferred by a speaker because it implies his/her goal provides the truth-conditions which determine the speaker's intended meaning in the specific situation of use. From this perspective, the determination of the speaker's intended meaning is viewed as a selection of a state of affairs which makes a sentence true (via truth-conditions) and satisfies the speaker's interest in situation (via goalconditions). Hence, the process of determining the speaker's intended meaning can be explained in terms of preferences ordering.

The schema in Figure 1 illustrates the notion of speaker's intended meaning as it is conceived here. ${ }^{12}$ At the bottom of the schema is a sentence which, given a context of use, has some plausible interpretations. Each interpretation refers to a state of affairs which makes the sentence true: that is, it refers to specific truth- 
conditions. The correspondence between the state of affairs preferred by the speaker and one of the states of affairs which make the sentence true determines the speaker's intended meaning. In other words, when the goal-conditions match the truth-conditions, we have speaker's intended meaning.

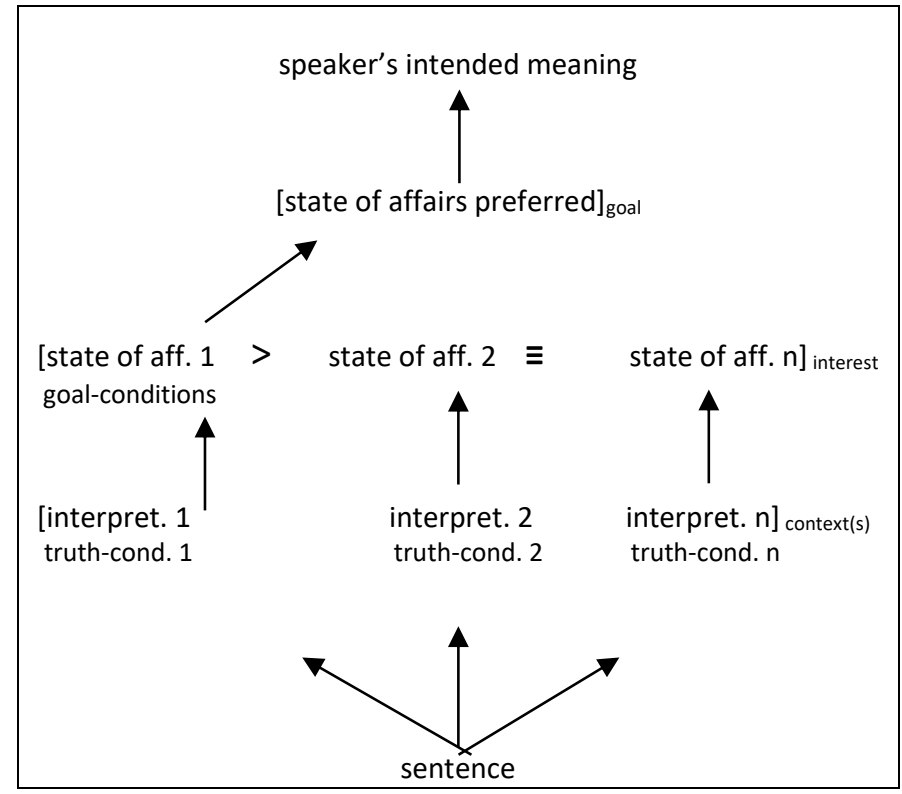

Figure 1 The schema illustrates the notion of speaker's intended meaning as it is conceived here

Addressee's intended meaning. The addressee's intended meaning is obtained via a communicative inference (Figure 2). The premise $\mathrm{P}_{1}$ consists of a sentence, the semantic conventions associated with its linguistic form, and contextual information (that is, some plausible meanings). The premise $\mathrm{P}_{2}$ consists of the addressee's belief about the speaker's interest, more specifically about a partial ordering of the speaker's preferences, and contributes to the intuitive truth-conditions.

$\mathrm{P}_{1}=$ Sentence (linguistic form, semantic conventions, context).

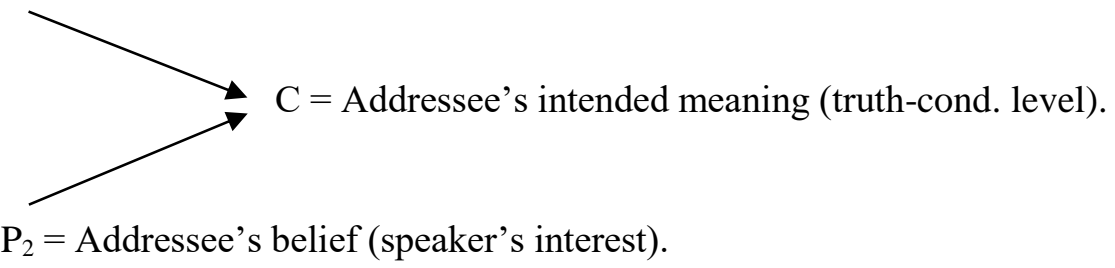

Figure 2 The schema illustrates the notion of addressee's intended meaning as it is conceived here. 
Before how the model works is described, the following section introduces some notions of the logic of preferences that will be used to account for the speaker's order of preferences and to express the contents of the addressee's belief.

\subsection{Preferences and state of affairs}

In philosophy and the logic of preference, the items of preference are generally states of affairs which are represented as sentences (see von Wright, 1963). This section introduces the notion of preference for states of affairs based on the comparative notions: "better than" (>), i.e. the strict preference relation, "equal in value to" $(\equiv)$, i.e. the indifference relation, and "at least good as" $(\geq)$, i.e. the weak preference relation. Using this language, it is possible to express the preferences of agents for states of affairs. ${ }^{13}$ For instance, on writing: $\left[\left(\mathrm{sa}_{1}\right)>\left(\mathrm{sa}_{2}\right)\right]_{\mathrm{Ag}}$, we assert that an agent prefers the state of affairs 1 rather than the state of affairs 2 (see Fig. 1).

Decisions theorists assume that an agent can rationally choose an option if the set of options satisfies the properties of completeness and transitivity. These properties are now defined.

Completeness for strict preference ( $>$ ) is defined as follows: ${ }^{14}$

the relation $>$ is complete if and only if for any elements $a$ and $b$ of its domain, either $a>b$ or $b>a$.

Transitivity for strict preference is defined as follows:

the relation > is transitive if and only if it holds for all elements $a, b$ and $c$ of its domain, so that if $a>b$ and $b>c$, then $a>c$.

These properties ensure that an agent is able to compare all options coherently with his/her own preferences. However, it may be that an agent is not always able to compare all options clearly, but this does not prevent him/her from choosing coherently with his/her own interest. Hence, in order to consider an agent's choice coherent with his/her interest, it is sufficient that $\mathrm{s} / \mathrm{he}$ is able to determine the best state of affairs among others without necessarily ordering the other states of affairs: that is, a partial ordering of preference is sufficient. ${ }^{15}$ In substance, considering the notion of partial order, it is not necessary for the set of states of affairs to be completely ordered; it is sufficient for the highest preference to be recognized, regardless of the relations among the other options.

The next subsection shows the role of the speaker's preferences in the interpretative process.

\subsection{How the model works}

Consider the following sentence:

3) "I lost the book yesterday." 
Situation: (3) is uttered by a writer who is completing his latest book. Yesterday he went to the library to borrow a book on Wittgenstein and had with him the draft of his new book with annotations on changes to its content. He proudly showed the draft to an employee of the library, whom he has known for a long time. Again yesterday, he bought at the town's best-known bookshop a new item for his bookshelf at home. When he went to the library he was carrying the bookshop bag with a heavy volume inside it. Today the writer has met the library employee strolling in the town centre and has uttered (3).

In this situation, (3) has at least three plausible meanings:

Meaning: [I lost the book on Wittgenstein yesterday.]

Meaning: [I lost the draft of my new book yesterday.]

Meaning: [I lost the book bought yesterday.]

What is the speaker's intended meaning? Is it the same as the addressee's?

Before showing how the addressee's communicative inference functions, we specify the speaker's potential goals and the preference relation for the states of affairs that make the various meanings of (3) plausible:

$G_{\text {Goal }}$ : Find the book on Wittgenstein (so as to save face).

Goal $_{2}$ : Find his book (so as not to lose the annotations).

Goal 3 : Find the book bought for his collection at home (so as not to lose the money paid for it).

Given the speaker's goals, we specify the preferences for the states of affairs that make the meanings of (3) plausible. In this example, we assume that the addressee gives most value to the work done on the draft (e.g., because it is irreplaceable) rather than the possible loss of face or the small amount of money spent on the book. Hence, the addressee's belief about the speaker's interest can be expressed in terms of order of preference for the states of affairs that make (3) true as follows:

$\left(s a_{2}\right):$ /I lost the draft of my new book yesterday/ > $\left(s a_{1}\right)$ : /I lost the book on Wittgenstein yesterday/

$\left(s a_{2}\right):$ /I lost the draft of my new book yesterday/ > $\left(s a_{3}\right):$ /I lost the book bought yesterday/

$\left(s a_{1}\right): / \mathrm{I}$ lost the book on Wittgenstein yesterday/ $\equiv\left(s a_{3}\right)$ : /I lost the book bought yesterday/

In short: $\left(s a_{2}\right)>\left(s a_{1}\right) \equiv\left(s a_{3}\right)$.

Hence the communicative inference is as follows: 
$\mathbf{P}_{1}=$ "I lost the book yesterday." $\left[M_{1} ; M_{2} ; M_{3}\right]_{\mathrm{ctx}}$

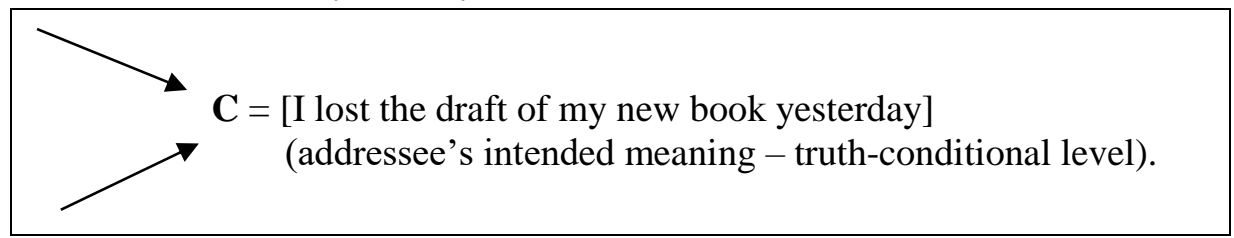

$\mathbf{P}_{2}=$ Addressee's belief $\left(\left(s a_{2}\right)>\left(s a_{1}\right) \equiv\left(s a_{3}\right)\right) \rightarrow($ goal-conditions $\leftrightarrow$ truthconditions $s_{2}$ ).

When the addressee's inference is based on a true belief about the speaker's interest, we have an effective communication, that is, a content sharing.

In what follows, the paper argues in favor of the inferential approach and of the role of the speaker's interest and the addressee's beliefs in explicit communication within the debate in pragmatics.

\section{Interest and Belief in Communication}

This section discusses the process of determining the shared intended meaning of an utterance within the debate in pragmatics. It argues in favor of the role of the speaker's interests and the addressee's belief concerning the speaker's interests in explicit communication.

As said, the conclusion of the inference in question consists of a unique proposition, the one explicitly expressed by the speaker with the utterance. Or, as in the case that follows, it consists of a part of the proposition that contributes, as the premise of another inference, to determination of the utterance's overall meaning. Consider the following sentence taken from the pragmatics literature (Carston, 2007).

4) "I'm going to the bank now to get some cash."

At first glance, here the interpretative problem consists in identifying a referent for the word "bank" ("financial institute" or "riverside"). Let us base our interpretation on the approach of Recanati's truth-conditional pragmatics. In this case it would be plausible to assume that the referent "financial institute" is assigned to the word "bank" because it is associated with the concept "cash" triggered by the word "cash," or because it is associated with the stereotypical representation "getting money from a bank" (or with both). This association is made possible by the discourse (or linguistic) context, i.e., the part of the sentence in which the expression "to get some cash" appears, and by the shared encyclopaedic knowledge that, in general, money is withdrawn from banks/financial institutes.

Following the same interpretation procedure, if at the beginning of utterance (4) the word "bank" is understood by the addressee in the sense of "riverside," because for some reason the latter concept is more activated and available to the addressee 
than "financial institute," it is likely that the word "cash" in the continuation of the sentence will trigger the concept "cash," which is associated with the concept of "financial institute," thus aligning the communication with the speaker's intentions (accessibility shift) (see Carston, 2007).

But this is not necessarily the intended interpretation, even though it is the most immediate one. Consider the case in which (4) is uttered by an angler who is going fishing and who intends to sell the fish that he catches. In this case, the encyclopaedic knowledge that money is withdrawn from banks is not relevant. But nor is the local knowledge that the speaker is a "professional" fisherman able to disambiguate the word "bank" (because also fishermen go to banks/financial institutes). Instead, if we know the speaker's interests - for example, that he intends to sell the fish that he catches in order to earn money, or that he intends to withdraw money in order to go shopping - then we are able to identify the intended referent in both the former and the latter case. We are able to do so on the basis of the knowledge shared between speaker and addressee about the speaker's interest, and not on the basis of conceptual associations produced by the addressee. If this is how matters stand, then it is plausible that the speaker's interests/goals and the addressee's beliefs render the communicative models more suitable for explicit communication (i.e. for truth-conditional content sharing) than to "mechanistic" models - or at least to more rigid ones based on conceptual frames and schemata activated by the addressee and presumed shared assumptions.

Presented below is the scheme of the inferential process whereby the addressee determines the meaning of (4):

"I'm going to the bank ${ }_{1,2}$ now to get some cash".

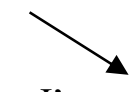

I'm going to the bank $\mathrm{1}_{1,2}$ now to get some cash [fishing and selling fish $]_{\text {enrichment }}$

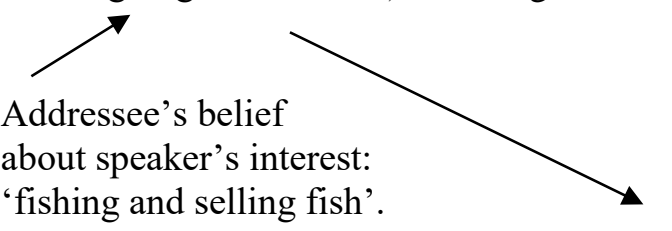

'fishing and selling fish'.

I'm going to the riverside now to get some cash by fishing and selling fish.

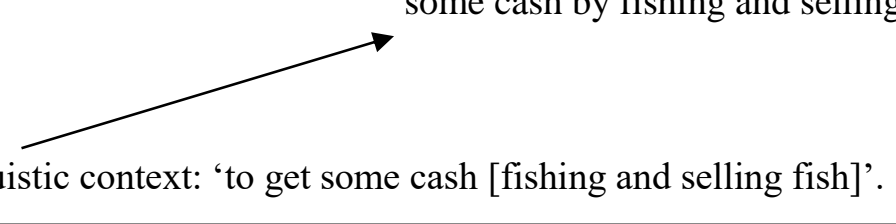

Figure 3 Inferential steps in determination of the meaning of (4). 
In interpretation of (4), the shared knowledge of the speaker's interest enables determination of the meaning of the expression "to get some cash" "fishing and selling fish") which then makes it possible to assign the reference for the word "bank" ("riverside"). Hence, the interest (via enrichment) has determined (i) the contribution of the expression "to get some cash" to the truth-conditions of the sentence, and accordingly (ii) the relevant linguistic context for disambiguation of "bank" in the specific situation.

Finally, an important characterization of the communication model is as follows. If we believe that knowledge of the speaker's interests is used in the premise of the addressee's inference, then we admit that the meta-representational capacities have a role in explicit communication. We therefore assume that, although this process is often automatic, in principle, the addressee can at any time justify, with respect to (4), the assignment of reference to the word "bank" or determination of modes in which "to get some cash."

\section{Conclusion}

The paper has presented a model of explicit communication for declarative sentences. The scope of the model relates to communicative situations in which contextual underdetermination is present and the addressee has specific information about the speaker's interests. The model's components have been: meaning as truth-conditions, inferential process, the speaker's interest as a state of affairs preferred by the speaker because it implies his/her goal; the partial ordering of states of affairs; and the addressee's belief about the speaker's interest. Its arguments have been: the communicative intentions that trigger the information of the pragmatic context are often not sufficient to select the speaker's intended meaning among some contextually plausible meanings (pars destruens), and thus it is necessary to take into account the partial order of preferences to determine the speaker's intended meaning (pars construens). Its related notions have been "what is said" and explicature. "What is said" refers to the explicit level of communication and is based on truth-theoretic machinery which delivers truth-conditions (Recanati, 2010). Nevertheless, the model differs from the truth-conditional pragmatics because it comprises the communicative inferences also for explicit meaning, and it considers as very relevant the active role of addressee in communication, as in the case of explicature in relevant theory (Wilson and Sperber, 2012).

As we have seen, the model is able to account for cases of the assignment of the reference of words and expressions through lexical modulation processes and disambiguation. The cases discussed have been resolved through the recognition of non-linguistic goals which have made it possible to order, according to the speaker's situational preferences, the states of affairs that make an utterance true with respect to a context or a combination of contexts. Shown in particular has been the assignment of reference for the word "book" in (3) and for the expression "to get some cash" and the word "bank" in (4) through free enrichment and disambiguation. 
Moreover, it has been shown how, through enrichment of the expression "to get some cash" in (4) and the subsequent assignment of reference, it has been possible to determine the linguistic context appropriate for resolving the ambiguity of the word "bank" in (4).

A further consideration is that the model discussed comprises two components of the shared intended meaning - i.e. the speaker's intended meaning and the addressee's intended meaning - which are obtained by different processes. With the notion of shared intended meaning thus conceived, it may be possible to explain in analogous manner both cases of communication and cases of miscommunication (based on the addressee's false beliefs).

Finally, now briefly outlined there are some answers to the questions posed in the introduction of the article. What is the contribution of context to the determination of propositional content? The context provides non-linguistic information essential for determination of the propositional content. As we have seen in (1), for example, the linguistic information triggered by the logical and linguistic form of a sentence is not sufficient to determine the meaning of that sentence. This is due to semantic underdeterminacy; and even with the aid of non-linguistic information available in the context is it not always possible to determine the intended meaning of an utterance because not all the contextual information is relevant or appropriate.

How is the relevant non-linguistic information triggered? The non-linguistic information that comes into play in interpretation of an utterance is mainly triggered by recognition of the speaker's goals and interests, which give access to information relevant to the situation of the utterance. As we have seen in (4), for example, the relevant knowledge is triggered on the basis of recognition of the speaker's activities in the situation.

And how is it used? Is it the premise of a non-demonstrative inference, or does it activate a frame that associates concepts? It is used as a premise in a nondemonstrative inference. Recourse to communicative inference presupposes a more (inter)active role by the addressee with respect to the association of concepts identified on the basis of presumed conceptual schemata shared by speaker and addressee. In other words, inference makes it possible to model the interaction on the basis of the relation between speaker and addressee which affords access to shared information, and not vice versa. In (4) for example, knowledge of the speaker's goals enables retrieval of information pertinent to the modulation of "to get some cash ['selling fish']" and consequently pertinent to disambiguation of the word "bank".

In summary, the speaker intends the meaning that maximizes his/her interest in situation, and the addressee infers the meaning on the basis of his/her belief about the speaker's partial order of preferences. We have shared intended meaning, that is, effective communication, when the addressee's inference is based on a true belief about the speakers' interest. 


\section{Disclosure statement}

The author has no financial interest or benefit arising from the direct application of this research.

\section{NOTES}

1. This article is an extended and revisited version of Cruciani, M. (2015). "An Interest and Belief-based Model of Explicit Communication," Proceedings of EuroAsianPacific joint conference on Cognitive Science, http://ceur-ws.org/Vol-1419/paper0036.pdf

2. On the notion of explicature, see Carston (2002); on "what is said," see Recanati (2001). More precisely, the expression "what is said" was originally proposed by Grice (1989).

3. More precisely, Recanati $(2004 a, 2010)$ distinguishes two levels of "what is said:" 'what is saidmin' that is obtained by bottom-up processes, and "what is saidint" that is obtained by top-down processes, where "int" stands for intuitive (truth-conditions) and "min" stands for minimal (role of pragmatics in content determination).

4. On inferential vs. associative methods, see Carston (2007); Recanati (2002b, 2004a, 2007); Wilson and Carston (2007). Moreover, for an argument in favor of relevance and the role of preferences in the communication process (contra the associative method), see Mazzarella (2011). For an argument in favor of the associative method and the role of schemata see Mazzone (2011).

5. Other kinds of lexical modulation are approximation or loosening/broadening (e.g., in "this piazza is round," "round" is used to mean "relatively round") and metaphorical extension (e.g. "tank" used to mean "forceful person"). In relevance theory, they are considered different outcomes of a single process which produces ad hoc concepts as result of an interaction among conventional meanings, contextual factors and pragmatic expectations (Wilson and Carston, 2007).

6. When Recanati uses the expression "free enrichment," by "free" he means nonmandatory, that is, optional (Recanati, 2010, 2012).

7. That is, objective features of the context of the utterance such as speaker, addressee, place, etc.

8. In this simple example, whose purpose is solely illustrative, not considered are the cases in which there is no water on Mars, in which there is water simultaneously in both gaseous and solid form, or in liquid form.

9. For example, Recanati (2010) does not consider the resolution of ambiguity to be a good counter-example to the fact that semantics and pragmatics do not mix, because semanticists do not consider disambiguation to be part of the semantic interpretation process. Perry (2000) treats it as a pre-semantic question to satisfy before a semantic evaluation can be made. Again, Belleri (2014) relates ambiguity to a case of underspecification (vs. semantic underdeterminacy): see also Travis (1997) and Bezuidenhout (2002). Bach (2012) does not consider ambiguity to be a true case of the context-dependence of meaning. However, the basic idea here is that in the communication process the addressee draws inferences to understand what the speaker is saying no matter what the source of underdeterminacy may be, and s/he does so by using any information available in the context that $\mathrm{s} / \mathrm{he}$ considers more appropriate/manageable.

10. This notion will be introduced in the following of this section. 
11. Note that here "Speaker's intended meaning" stands for "Speaker's explicit intended meaning."

12. The level of the interest in Figure 1 represents an order of preference, where ">" stands for the preference relation: "better than," and "三”" stands for the preference relation: "equal in value to," as specified in the following part of the paper.

13. For an overview on the logic of preference in philosophy see Hansson and GrüneYanoff (2012). “三”.

14. Analogously we can define completeness and transitivity for the relations " $\geq$ " and

15. More precisely, a partial order requires satisfaction of the reflexive, transitive and asymmetric properties; and a strict partial order requires satisfaction of the irreflexive and transitive properties (see Hansson and Grüne-Yanoff, 2012). Reflexivity is considered a property that guarantees a pre-order, and asymmetry is derived from transitivity.

\section{REFERENCES}

Bach, Kent (2004). "Minding the Gap," in Claudia Bianchi (ed.), The Semantics/Pragmatics Distinction. Stanford, CA: CSLI, 27-43.

-- (2010). "Impliciture vs Explicature: What's the Difference?", in Esther Romero and Belén Soria (eds.), Explicit Communication: Robyn Carston's Pragmatics. Dordrecht: Springer, 126-137.

-- (2012). "Context Dependence," in Manuel Garcia-Carpintero and Max Kölbel (eds.), The Continuum Companion to the Philosophy of Language. London: Continuum, 153184.

Belleri, Delia (2013). "Meta-representation in Utterance Comprehension," Journal of Pragmatics 57: 158-169.

-- (2014). Semantic Under-determinacy and Communication. Basingstoke: Palgrave Macmillan.

Bezuidenhout, Anne (2002). "Truth-Conditional Pragmatics," Philosophical Perspectives 16: $105-34$.

Bianchi, Claudia (ed.) (2004). The Semantics/Pragmatics Distinction. Stanford, CA: CSLI.

Borg, Emma (2012). Pursuing Meaning. Oxford: Oxford University Press.

Cappelen, Herman (2007). "Semantics and Pragmatics: Some Central Issues," in Gerhard Preyer and Georg Peter (eds.), Context-sensitivity and Semantic Minimalism. Oxford: Oxford University Press, 3-22.

Cappelen, Herman, and Ernie Lepore (2005). Insensitive Semantics: A Defense of Semantic Minimalism and Speech Act Pluralism. Oxford: Blackwell.

Carston, Robyn (1997). "Enrichment and Loosening: Complementary Processes in Deriving the Proposition Expressed?", Linguistische Berichte 8: 103-127

-- (2002). Thoughts and Utterances: The Pragmatics of Explicit Communication. Oxford: Blackwell.

-- (2007). "How Many Pragmatic Systems Are There?", in Maria José Frapolli (ed.), Saying, Meaning, Referring. New York: Palgrave, 18-54.

-- (2008). "Linguistic Communication and the Semantic/Pragmatics Distinction," Synthese 165(3): 321-345. 
Carston, Robyn, and Alison Hall (2012). "Implicature and Explicature," in Hans-Jörg Schmid (ed.), Cognitive Pragmatics. Handbooks in Pragmatics. Berlin: De Gruyter, 4784.

Conte, Rosaria, and Cristiano Castelfranchi (1995). Cognitive and Social Action. London: University College London Press.

Corazza, Eros, and Jérôme Dokic (2012). "Situated Minimalism vs. Free Enrichment," Synthese 184(2): 179-198.

Gauker, Christopher (2012). "Semantics and Pragmatics," in Delia Graff Fara and Gillian Russell (eds.), Routledge Companion to the Philosophy of Language. Oxford: Routledge, $18-28$.

Grice, Herbert P. (1989). Studies in the Way of Words. Cambridge, MA: Harvard University Press.

Hall, Allison (2014). "“Free' Enrichment and the Nature of Pragmatic Constraints," International Review of Pragmatics 6(1): 1-28.

Hansson, Sven O., and Till Grüne-Yanoff (2012). "Preferences," in The Stanford Encyclopedia of Philosophy, http://plato.stanford.edu/archives/win2012/entries/preferences/

Kaplan, David (1989). "Afterthoughts," in Joseph Almog, John Perry and Howard Wettstein (eds.), Themes from Kaplan. Oxford: Oxford University Press, 565-614.

Levinson, Stephen (2000). Presumptive Meanings. Cambridge, MA: MIT Press.

Mazzarella, Daniela (2011). "Accessibility and Relevance. A Fork in the Road," in UCL Working Papers in Linguistics 23.

Mazzone, Marco (2011). "Schemata and Associative Processes in Pragmatics," Journal of Pragmatics 43(8): 2148-2159.

Penco, Carlo, and Filippo Domaneschi (eds.) (2013). What Is Said and What Is Not. Stanford, CA: CSLI.

Perry, John (2000). The Problem of the Essential Indexical and Other Essays. Stanford, CA: CSLI.

Recanati, François (2001). "What Is Said,” Synthese 128: 75-91.

-- (2002a). "Inarticulated Constituents," Linguistic and Philosophy 25(3): 299-345.

-- (2002b). "Does Linguistic Communication rest on Inference?", Mind \& Language 17: $105-126$.

-- (2004a). Literal Meaning. Cambridge: Cambridge University Press.

-- (2004b). "What is said' and the Semantics/Pragmatics Distinction," in Claudia Bianchi (ed.), The Semantics/Pragmatics Distinction. Stanford, CA: CSLI.

-- (2007). "Reply to Carston," in Maria José Frapolli (ed.), Saying, Meaning, Referring. New York: Palgrave, 49-54.

-- (2010). Truth-Conditional Pragmatics. Cambridge: Cambridge University Press.

-- (2012). "Contextualism: Some Varieties," in Keith Allan and Kasia Jasczolt (eds.), The Cambridge Handbook of Pragmatics. Cambridge: Cambridge University Press, 135-149.

Searle, John R. (1980). “The Background of Meaning," in John R. Searle, Ferenc Kiefer, and Manfred Bierwisch (eds.), Speech Act Theory and Pragmatics. Dordrecht: Reidel, 221232.

Sperber, Dan, and Deirdre Wilson (1986). Relevance Theory: Communication and Cognition. Oxford: Blackwell.

-- (2002). "Pragmatics, Modularity and Mind-Reading," Mind \& Language 17: 3-23.

Stalnaker, Robert (2014). Context. Oxford: Oxford University Press.

Stanley, Jason (2000). “Context and Logical Form," Linguistics \& Philosophy 25: 701-721. 
Stojnic, Una, and Ernie Lepore (2013). “What's What Is Said?', in Carlo Penco and Filippo Domaneschi (eds.), What Is Said and What Is Not. Stanford, CA: CSLI.

Szabó, Zoltan (ed.) (2005). Semantics vs. Pragmatics. Oxford: Oxford University Press.

Travis, Charles (1975). Saying and Understanding. Oxford: Blackwell.

-- (1997). "Pragmatics," in Bob Hale and Crispin Wright (eds.), A Companion to the Philosophy of Language. Oxford: Blackwell, 87-107.

von Wright, Georg H. (1963). The Logic of Preference. Edinburgh: Edinburgh University Press.

Wilson, Deirdre (2014). "Relevance Theory," in Yan Huang (ed.), Oxford Handbook of Pragmatics. Oxford: Oxford University Press, 129-148.

Wilson, Deirdre, and Robyn Carston (2007). "A Unitary Approach to Lexical Pragmatics: Relevance, Inference and Ad Hoc Concepts," in Noel Burton-Roberts (ed.), Pragmatics. Basingstoke: Palgrave Macmillan, 230-260.

Wilson, Deirdre, and Dan Sperber (2012). Meaning and Relevance. Cambridge: Cambridge University Press. 